\title{
A NATUREZA DA HIERARQUIA ENTRE LEI COMPLEMENTAR E LEI ORDINÁRIA EM MATÉRIA TRIBUTÁRIA
}

\section{THE NATURE OF THE HIERARCHY BETWEEN SUPPLEMENTARY LAWS AND ORDINARY LAWS IN TAX MATTERS}

\author{
Paulo de Barros Carvalho \\ Pontifícia Universidade Católica de São Paulo - PUC-SP - (São Paulo, SP, Brasil) \\ Universidade de São Paulo - USP - (São Paulo, SP, Brasil) \\ Sérgio Serafim Aquino \\ Secretaria da Fazenda e Planejamento do Estado de São Paulo (São Paulo, SP, Brasil) \\ Recebimento: 28 jun. 2019 \\ Aceitação: 20 set. 2019
}

\begin{abstract}
Como citar este artigo / How to cite this article (informe a data atual de acesso / inform the current date of access):
CARVALHO, Paulo de Barros; AQUINO, Sérgio Serafim. A natureza da hierarquia entre lei complementar e lei ordinária em matéria tributária. Revista da Faculdade de Direito UFPR, Curitiba, PR, Brasil, v. 65, n. 1, p. 81-99, jan./abr. 2020. ISSN 2236-7284. Disponível em: <https://revistas.ufpr.br/direito/article/view/67676>. Acesso em: 30 abr. 2020. DOI: http://dx.doi.org/10.5380/rfdufpr.v65i1.67676.
\end{abstract}

\section{RESUMO}

A lei complementar ostenta uma posição de destaque em matéria tributária, particularmente em função do papel a ela atribuído pela Constituição da República em seus artigos 59, parágrafo único, e 146, III. Em razão disso, desde que a lei complementar ingressou no ordenamento jurídico pátrio, doutrina e jurisprudência têm se debruçado sobre esse tipo normativo procurando estabelecer a sua relação com os demais diplomas legais, em especial com a lei ordinária. Com fundamento nas mais diversas premissas, ora as teses apontam para a existência de hierarquia entre lei complementar e lei ordinária, ora para a inexistência de hierarquia, argumentando-se que tudo não passaria de uma questão de reserva material definida na própria Constituição da República. Ao longo desta pesquisa foram exploradas correntes doutrinárias e jurisprudenciais a respeito do assunto, com especial atenção aos seus fundamentos. Ao final da pesquisa, concluiu-se que, embora existente em determinadas situações, a hierarquia entre lei complementar e lei ordinária em matéria tributária não tem como pressuposto a espécie normativa em si, mas o seu conteúdo.

\section{PALAVRAS-CHAVE}

Lei Complementar. Lei Ordinária. Hierarquia. Reserva Material. Normas Gerais.

\begin{abstract}
Supplementary laws hold a key position in tax matters, particularly due to the role they were assigned by the Brazilian Constitution under Article 59, sole paragraph, and Article 146, III. As a result, ever since supplementary laws were introduced in the Brazilian legal system, legal scholars and the Courts have been addressing the novel normative type in order to establish its relationship to other types of legislation, with ordinary laws in particular. Based on various arguments, some opinions point to the existence of a hierarchical relationship between supplementary laws and ordinary laws, and other opinions argue there is no hierarchy between them and it is a question of material reserve enshrined
\end{abstract}


in the Federal Constitution. Throughout this study scholarly reasoning and case law were examined, with a focus on their grounds. Finally, this study concludes that although a hierarchical relationship exists in certain situations, the hierarchy between supplementary laws and ordinary laws in tax matters is not based on the type of norm per se, but rather on their content.

\section{KEYWORDS}

Supplementary Law. Ordinary Law. Hierarchy. Material Reserve. General Norms.

\section{INTRODUÇÃO}

O presente artigo tem como propósito trazer a lume uma contribuição à discussão envolvendo a temática da relação hierárquica entre lei complementar e lei ordinária em matéria tributária enquanto veículos introdutores de normas no sistema jurídico. Adverte-se que o tema já foi objeto de exame por estudiosos do direito tributário nacional, o que, se por um lado minimiza os esforços investigativos do pesquisador, por outro o submete a uma profusão de argumentos nem sempre convergentes.

Em consonância com o delineado no artigo inaugural da Carta Magna, a República Federativa do Brasil comporta ordens jurídicas parciais que regulam as relações interpessoais ocorridas no âmbito de suas pessoas políticas União, estados, Distrito Federal e municípios, guardando entre si apenas vínculos de coordenação, afastadas quaisquer aspirações de ordem hierárquica. No que interessa a este trabalho, destaca-se, de início, a lei nacional, expressão dos estados federais, que alcança indistintamente todas as pessoas políticas, tendo como objeto determinadas matérias delineadas na Constituição da República. Neste particular, em trabalho primoroso, Geraldo Ataliba (1969, p. 49) alerta para a distinção necessária entre lei federal e lei nacional, a primeira dirigida à União e a segunda dirigida aos entes federativos, guardando como traço comum sua origem no legislativo federal.

A peculiar vocação das leis nacionais para a veiculação de normas gerais na esfera da competência concorrente, nos termos do artigo 24, § $1^{\circ}$, da Constituição da República, tem o condão de alçá-las a uma posição proeminente nos quadrantes deste trabalho. Saliente-se que, na abalizada lição de José Souto Maior Borges (1975, p. 71-72), as leis nacionais podem assumir a forma de lei complementar ou lei ordinária, sempre em conformidade com o disposto na Lei Maior:

Assim sendo, tanto a lei complementar, quanto a lei ordinária da União podem revestir-se ou não do caráter de leis nacionais, em função dos respectivos conteúdos e âmbitos pessoais de validade, sendo de rechaçar-se a opinião dos que sustentam indiscriminadamente ser a lei complementar uma lei essencialmente nacional. 
Nada obstante, nos termos do artigo 146, III, da Constituição da República, coube à lei complementar a função de estabelecer normas gerais em matéria de legislação tributária. A partir desse comando constitucional, desvela-se uma série de questões que vêm sendo tratadas pela doutrina e jurisprudência, nem sempre de modo convergente, compreendendo as relações observadas entre lei complementar e lei ordinária em matéria tributária, especialmente no que se refere à existência de hierarquia entre elas. As premissas adotadas pelos que se debruçaram sobre a matéria foram investigadas na busca de soluções possíveis para as questões postas à discussão. Coube, ainda, à lei complementar, nos termos do artigo 59, parágrafo único, da Constituição da República, o papel de dispor sobre a elaboração, redação, alteração e consolidação das leis.

Os caminhos trilhados pelo Judiciário, inspirado pelo debate de ideias no âmbito doutrinário, acabam por interferir no modo de produção e controle dessas espécies normativas, repercutindo no planejamento tributário dos agentes econômicos. Diante desse quadro, tornam-se extremamente oportunas as investigações ora propostas.

A hipótese que se pretende investigar aponta em direção à existência de uma superioridade hierárquica apenas reflexa entre lei complementar e lei ordinária em matéria tributária, pois se constata que o fundamento dessa relação normativa está associado ao conteúdo da lei complementar e não à sua forma, como pode parecer em uma análise preliminar.

\section{HIERARQUIA ENTRE LEI COMPLEMENTAR E LEI ORDINÁRIA EM MATÉRIA TRIBUTÁRIA}

Nesta seção serão discutidas as particularidades e inter-relações destas duas espécies normativas.

\subsection{BREVE HISTÓRICO DA LEI COMPLEMENTAR EM MATÉRIA TRIBUTÁRIA}

Foi na Constituição de 1967 que, de modo vestibular, se atribuiu à lei complementar o papel de veículo introdutor das normas gerais de direito tributário, inovação mantida pela Emenda Constitucional $n^{0} 1$ de 1969. Nesse sentido, Geraldo Ataliba (1969, p. 58):

Entre as inovações trazidas pela Carta de 1967 e mantidas pela Emenda Constitucional n.1 é importante a disposição do $\S 1^{\circ}$ do art. 18, que dispõe que "lei complementar estabelecerá normas gerais de Direito Tributário, disporá sôbre os conflitos de competência nessa matéria entre a União, os Estados, o Distrito Federal e os Municípios e regulará as limitações constitucionais do poder de tributar”. 
A título de registro, consigne-se a oportuna intervenção de Rubens Gomes de Sousa (2007, p. 17-18) com o objetivo de examinar o texto do Código Tributário Nacional (Lei nº 5.172/1966), que resgata episódio no qual é revelada a prosaica origem da expressão “normas gerais”, cuja importância seminal reclama transcrição nos moldes a seguir:

A única limitação, que ele próprio enxergava, era a de se tratar de preceitos comuns aos três legisladores. Afora isto, ele não via e não achava necessário delimitar, de outra maneira, a competência que queria fosse atribuída ao Legislativo da União, que já então ele concebia, neste setor e em outros paralelos, não como federal, mas sim nacional. Entretanto, ele encontrou resistência política, de se esperar e muito forte, em nome da autonomia dos Estados e da autonomia dos Municípios, em nome de temores, justificados ou não, de se abrir uma porta, pela qual se introduzisse o fantasma da centralização legislativa. Falou-se nada menos do que a própria destruição do regime federativo, todos os exageros verbais, que o calor do debate político comporta e o próprio Aliomar encontrou uma solução de compromisso, que foi a de delimitar-se essa competência, que ele queria ampla, pelas normas gerais, expressão que, perguntado por mim quanto ao sentido que ele lhe dava, no intuito de ter uma forma de interpretação autêntica, ele me confessou que não tinha nenhuma, que nada mais fora do que um compromisso político, que lhe havia ocorrido e que tinha dado certo.

A Carta de 1988 manteve a tradição de atribuir à lei complementar o estabelecimento de normas gerais em matéria tributária, não obstante a constituição anterior fizesse referência a normas gerais de direito tributário, e inovou ao tratar a lei complementar como o veículo normativo adequado para dispor sobre a elaboração, redação, alteração e consolidação das leis.

Feitas essas breves considerações de cunho histórico, passa-se a dissertar sobre os pontos de contato entre lei complementar e lei ordinária, bem como sobre os caracteres que lhes trazem distinção.

\subsection{LEI COMPLEMENTAR E LEI ORDINÁRIA NA CONSTITUIÇÃO DA REPÚBLICA}

As leis complementares e ordinárias guardam identidade com relação à iniciativa para sua edição, conforme previsto no caput do artigo 61 da Constituição da República. Com relação à sua aprovação pelo parlamento, as leis complementares destacam-se por sua forma mais rigorosa no tocante ao quórum. Enquanto as leis ordinárias são aprovadas pela maioria de votos das casas legislativas, nos termos do artigo 47 da Constituição da República, as leis complementares reclamam maioria absoluta, conforme o artigo 69. A maior rigidez na aprovação das leis complementares associada à reserva material estabelecida na Lei Maior evoca a opção feita pelo legislador constituinte em salvaguardar essas matérias contra maiorias fugazes no Congresso Nacional. Essas matérias 
reservadas à lei complementar escapam, ainda, de sua veiculação por meio de medidas provisórias e leis delegadas, à luz da previsão constitucional dos artigos 62 , § $1^{\circ}$, III, e 68 , $\S 1^{\circ}$, respectivamente.

Além dos já mencionados comandos normativos inseridos nos artigos 146, III, e 59, parágrafo único, ao longo da Constituição da República é possível encontrar outras indicações de matérias reservadas à lei complementar, de modo expresso ou implícito nas dobras da interpretação dos comandos constitucionais. Às leis ordinárias restam residualmente as demais matérias. Consignese que a constatação da existência de uma reserva material relacionada à lei complementar na Constituição da República não sinaliza per se em direção ao amesquinhamento da autonomia parlamentar, vedando-se a veiculação de outras matérias por essa espécie legislativa. De outra parte, também não se pode afirmar que se trata de um núcleo não exaustivo de matérias a ser veiculado por lei complementar, podendo esse rol ser ampliado ao talante do legislador. Entretanto, dado o objeto das presentes investigações, considerações de tal espécie serão apenas tangenciadas naquilo que forem relevantes ao desenvolvimento deste trabalho.

\subsection{CONTEÚDO SEMÂNTICO DA EXPRESSÃO HIERARQUIA NORMATIVA}

Para prosseguimento das investigações revela-se fundamental a definição do conceito de hierarquia normativa. Antes da delimitação do conteúdo semântico da locução hierarquia normativa, porém, cabe uma breve digressão acerca das imprecisões associadas ao contexto comunicacional.

Segundo Hospers (1976, p. 17), por um longo período pensou-se que as palavras tivessem uma relação natural com o objeto representado, de modo que "la palabra no podía ser 'correctamente' usada para representar otra cosa”. Sabe-se hoje que as palavras não encerram essa conexão natural com os objetos representados, uma vez que são apenas signos que representam arbitrariamente esses objetos. Como advertem Guibourg, Ghigliani e Guarinoni (1991, p. 34, grifo dos autores), "Cuando aprendemos el nombre de una cosa, entonces, no aprendemos algo acerca de la cosa, sino sobre las costumbres lingüísticas de cierto grupo o pueblo: el que habla el idioma donde ese nombre corresponde a esa cosa”.

Além da ilusão da referencialidade entre os nomes e os objetos representados, vale destacar que as palavras são potencialmente ambíguas e vagas. Essa falta de univocidade entre os nomes e seus significados, atributo fundamental para a construção da linguagem científica, acaba por prejudicar o processo comunicacional.

As palavras são ambíguas na medida em que podem possuir mais de um significado, comprometendo a eficácia do discurso. Além disso, “[...] prácticamente todas las palabras son vagas 
en alguna medida”, conforme avaliam Guibourg, Ghigliani e Guarinoni (1991, p. 48, grifo dos autores). Dessa forma, existe um conjunto de casos em que as palavras podem ser utilizadas ou deixar de ser utilizadas sem nenhum tipo de contestação. Entretanto, existe uma zona de penumbra na qual nada se pode afirmar acerca da utilização dessas palavras sem o uso de critérios adicionais para precisar seu significado. Diante do exposto, com o objetivo de superar as imprecisões associadas ao contexto comunicacional, cumpre delimitar o sentido em que a expressão hierarquia normativa será utilizada neste trabalho.

Toma-se hierarquia normativa como a relação existente entre normas jurídicas por meio da qual determinadas normas buscam seu fundamento de validade em outras. Nesse sentido, a norma jurídica hierarquicamente superior regula a produção das normas que lhe são inferiores.

Na medida em que a produção das normas jurídicas pode envolver questões de forma e conteúdo das unidades produzidas, abre-se espaço para que o tema da hierarquia normativa possa ser examinado em seus aspectos formal e material.

Tendo sido delimitado o conteúdo semântico da hierarquia formal e material, resta saber se esses conceitos são aplicáveis à lei complementar tributária em sua relação jurídica com a lei ordinária ou se a relação entre essas espécies normativas se limita apenas à divisão de matérias nos termos delineados na Constituição da República.

\subsection{ESPÉCIES DISTINTAS DE LEIS COMPLEMENTARES}

A controvérsia envolvendo a questão da existência de hierarquia entre lei complementar e lei ordinária em matéria tributária pode ser creditada em grande parte a uma percepção equivocada acerca do papel desempenhado pelas leis complementares na Constituição da República. É preciso atentar para o fato de que nem toda lei complementar reclamada pela Carta Magna vai exercer a função de fundamento de validade de outros diplomas normativos, sendo algumas delas apenas fundamento para o exercício de competências da União enquanto ente político.

Já na década de 70 do século passado, José Souto Maior Borges (1975, p. 83) antevia a distinção existente entre as diferentes funções reservadas à lei complementar pelo texto constitucional:

A doutrina brasileira, consoante exposto, vislumbra indistintamente uma função de intermediação ou intercalar da lei complementar, decorrente de sua inserção formal, na enunciação dos atos normativos do art. 46 da Constituição, entre as emendas constitucionais e as leis ordinárias. Tal entretanto nem sempre ocorre, como o demonstra uma análise jurídica mais detida. Essa análise revelará dois grupos básicos de leis complementares: $1 .^{\circ}$ ) leis complementares que fundamentam a validade de atos normativos (leis ordinárias, decretos 
legislativos e convênios); e 2..$^{\circ}$ ) leis complementares que não fundamentam a validade de outros atos normativos. Não parece viável, fora dessa perspectiva, uma classificação das leis complementares.

De fato, uma singela análise de comandos constitucionais em matéria tributária que reivindicam lei complementar no trato de determinados temas é suficiente para validar esse raciocínio. Notadamente, o artigo 148, que trata dos empréstimos compulsórios, o 153, VII, que trata do imposto sobre grandes fortunas, e o 154, I, que trata da competência residual da União, dispõem sobre temas que, uma vez normatizados, darão origem a leis complementares cuja função se exaure na instituição dos referidos tributos, não se prestando a funcionar como fundamento de validade de outros diplomas normativos. Por sua vez, o já mencionado artigo 146, III, da Constituição da República, ao dispor que cabe à lei complementar estabelecer normas gerais em matéria de legislação tributária, está atribuindo a essa lei complementar o papel de fundamento de validade material das leis ordinárias versando sobre matéria tributária.

Por seu turno, o parágrafo único do artigo 59 da Carta Magna estabelece que lei complementar disporá sobre elaboração, redação, alteração e consolidação das leis, atribuindo a essa lei complementar o papel de fundamento de validade formal das demais leis em sentido amplo, no que, por óbvio, também se incluem as leis ordinárias em matéria tributária.

Assinaladas as previsões constitucionais relativas à edição de leis complementares que fundamentam material e formalmente a validade das leis ordinárias em matéria tributária, resta identificar essas leis complementares no ordenamento jurídico pátrio e esclarecer em que medida elas podem ser consideradas hierarquicamente superiores às leis ordinárias que tratam de matéria tributária, considerando o conceito de hierarquia normativa adotado.

Antes, porém, vale discorrer sobre a lei nacional e também sobre as normas gerais, conceitos que reclamam compreensão para o adequado manejo dos temas envolvidos na controvérsia apresentada.

\subsection{LEI NACIONAL E NORMAS GERAIS}

Editado como lei ordinária, o Código Tributário Nacional foi recepcionado pela Carta de 1988, conforme previsão do artigo 34, § 5º do Ato das Disposições Constitucionais Transitórias, ostentando o status de lei complementar.

Hugo de Brito Machado (2010, p. 166) ressalva que, embora só possa ser alterado por meio de lei complementar, em razão do status alcançado por força do que dispõe o artigo 146, III, da Lei Maior, o fenômeno da recepção constitucional não atribuiu ao Código Tributário Nacional a natureza 
de lei complementar, tendo remanescido sua feição ordinária. Segundo o autor, “a recepção de uma norma por uma nova ordem constitucional não confere a essa norma qualidade formal que não tinha”. Tendo ingressado no ordenamento jurídico como lei ordinária, mantém essa natureza, ainda que seus dispositivos somente possam ser alterados por meio de lei complementar. Consigne-se que não é escopo deste trabalho examinar se o Código Tributário Nacional veicula disposições que extrapolam os limites relativos à matéria tributária, o que poderia suscitar controvérsia acerca da espécie normativa exigida para sua revogação.

Típica lei nacional veiculando normas gerais em matéria tributária, o Código Tributário Nacional alcança indistintamente União, estados, Distrito Federal e municípios, não podendo as pessoas políticas legislar em matéria tributária contrariando seus comandos normativos. Conforme já anotado, embora editadas pelo Congresso Nacional, as leis nacionais não se confundem com as leis federais que vinculam somente a União. Nos Estados federais, as leis nacionais veiculam normas gerais aplicáveis a todos os entes federados.

Embora essas assertivas envolvendo a lei nacional e as normas gerais por ela veiculadas forneçam elementos significativos para apreciação das indagações relativas à relação hierárquica entre lei complementar e lei ordinária, antes de enfrentar o tema proposto por este trabalho cabe ainda uma reflexão acerca do posicionamento da jurisprudência e de parcela da doutrina nacional que, ignorando a existência de hierarquia nos termos propostos, ora sustenta que a discussão se resume a uma questão de reserva material posta pela Constituição da República, vindo a conferir campos normativos distintos às mencionadas leis, ora vislumbra relação hierárquica sob fundamentos diversos.

\subsection{HIERARQUIA NORMATIVA NA DOUTRINA E NA JURISPRUDÊNCIA}

A afirmação de que o fundamento de validade das leis se encontra na Constituição da República, embora acertada, não se presta a negar a existência de hierarquia normativa no âmbito infraconstitucional. Não se trata de assertivas mutuamente excludentes. Harmonizando a questão, vale considerar que a lei ordinária tributária busca seu fundamento de validade imediatamente na lei complementar tributária e mediatamente na Constituição da República, conforme intuiu Regina Helena Costa (2014, p. 42).

A existência de dois grupos distintos de leis complementares, a despeito de compreender reflexões de cunho hierárquico, também contempla considerações relacionadas à reserva material. Em consequência, investigações acerca do reconhecimento de relação hierárquica entre espécies 
normativas não pode declinar reflexões acerca do conteúdo das normas analisadas, sob pena de serem tratadas de modo indiscriminado realidades diversas.

A respeito da existência de hierarquia normativa, Celso Ribeiro Bastos (1999, p. 72) proclama:

No que diz respeito a [sic] relação existente entre lei complementar e lei ordinária, vale ressaltar, [sic] que a lei ordinária retira a sua validade da sua conformidade com a Constituição e não da lei complementar como gostariam aqueles que defendem a superioridade hierárquica desta última em relação a [sic] lei ordinária. [...] A lei ordinária tem um campo material diferente do da lei complementar, poderíamos dizer que seu campo de atuação é um campo residual, na denominação do Prof. Michel Temer.

Com efeito, Michel Temer (2014, p. 150) sustenta a inexistência de hierarquia entre lei complementar e lei ordinária, nos seguintes termos:

É por exclusão, pois, que se alcança o âmbito material da lei ordinária. Não há hierarquia alguma entre a lei complementar e a lei ordinária. O que há são âmbitos materiais diversos atribuídos pela Constituição a cada qual destas espécies normativas.

A existência de superioridade hierárquica da lei complementar, por sua vez, é defendida por Hugo de Brito Machado (2010, p. 154-155) por meio de argumento peculiar:

É evidente, porém, que a hierarquia superior resulta exatamente da maior rigidez assumida pela espécie normativa. Não pelo simples fato de haver sido eventualmente aprovada por determinado quórum. Uma lei ordinária evidentemente não se transforma em lei complementar pelo simples fato de haver sido aprovada por maioria absoluta. Nem se transforma em emenda constitucional por haver sido aprovada por mais de três quintos dos parlamentares. Aliás, quanto às emendas a Constituição exige sejam votadas em dois turnos, o que afasta desde logo o infeliz argumento. Em qualquer caso, o que caracteriza a espécie normativa é o procedimento adotado em sua apreciação e aprovação pelo Congresso Nacional. [...] Na verdade, a hierarquia superior resulta precisamente da maior rigidez no procedimento ao qual se submete a espécie normativa.

Por seu turno, Frederico Araújo Seabra de Moura (2009, p. 101-102, grifo do autor) acolhe a tese da existência de hierarquia entre as normas em determinadas situações:

Quadra advertir que a hierarquia entre as normas somente se dá na ocasião de uma delas servir de fundamento de validade para a outra, seja no aspecto formal, seja no aspecto material. [...] Pode a norma superior indicar ou o órgão competente ou o processo a ser obedecido para criação da norma inferior, ou ainda delimitar-lhe o conteúdo material. [...] Contudo, não há de se falar que a lei complementar é sempre superior hierarquicamente à lei ordinária. Esse é um equívoco rotundo, segundo Vitor Nunes Leal. Pode vir a ser, mas unicamente quando servir de fundamento de validade - formal ou material - para uma lei ordinária, o que não ocorre sempre.

O entendimento de Regina Helena Costa (2014, p. 42, grifo da autora) sobre o tema remete aos mesmos fundamentos: 
Cremos mais adequado o entendimento segundo o qual não existe uma hierarquia necessária entre a lei complementar e a lei ordinária, porquanto ambas, em regra, retiram seu fundamento de validade diretamente da Lei Maior. Falamos em hierarquia necessária porque, eventualmente, ela pode se verificar. É o que ocorre na hipótese de a lei ordinária encontrar seu fundamento de validade também na lei complementar. Nesse caso, então, a lei ordinária extrairá seu fundamento de validade mediatamente da Constituição e imediatamente da lei complementar. Certo é, portanto, existirem leis complementares que outorgam fundamento de validade à lei ordinária e outras que, diversamente, não cumprem essa função.

A impossibilidade de se defender uma visão unitária sobre as leis complementares tem como exemplo eloquente as regras estabelecidas para dirimir conflitos de competência entre os entes tributantes. Trata-se, portanto, de hierarquia material, em que os comandos da lei complementar relativos às matérias a ela constitucionalmente reservadas deverão ser observados pelo legislador ordinário.

Adentrando nos domínios da hierarquia formal, avulta-se a falta de vocação da Lei Complementar n ${ }^{\circ}$ 95/1998, que dispõe "sobre a elaboração, a redação, a alteração e a consolidação das leis” (BRASIL, 1998), para dispor sobre o conteúdo de outros diplomas legais, e evidencia-se sua superioridade hierárquica formal em relação às demais espécies normativas. Nesse sentido, Frederico Araújo Seabra de Moura (2009, p. 104) sustenta a superioridade formal da mencionada lei complementar em relação aos demais diplomas normativos, servindo-lhes de fundamento de validade.

Como se observa, a cambiante doutrina sobre o tema hierarquia normativa vai buscar suporte para suas assertivas nas particularidades da lei complementar nos termos em que foi posta na Constituição da República, ora dando ênfase a determinados aspectos, ora a outros. Deve-se ponderar, no entanto, que a existência de dois grupos distintos de leis complementares ofusca qualquer esforço na busca de uma única perspectiva sobre a questão.

Tendo sido apresentadas respeitáveis posições doutrinárias envolvendo a relação hierárquica entre lei complementar e lei ordinária, cumpre examinar manifestações dos tribunais superiores a respeito do tema.

Apreciando a matéria no RE 377.457/PR (BRASIL, 2008a), o Supremo Tribunal Federal (STF) sufragou a inexistência de relação hierárquica entre lei complementar e lei ordinária, defendendo a tese da reserva material constitucionalmente posta. Nessa linha, os ministros da Suprema Corte votaram pela revogação por meio de lei ordinária da isenção da Contribuição para o Financiamento da Seguridade Social (Cofins) concedida nos termos do artigo $6^{\circ}$, II, da Lei Complementar $n^{\circ}$ 70/1991 às sociedades civis de prestação de serviços de profissão legalmente regulamentada, conforme ementa: 
EMENTA: Contribuição social sobre o faturamento - COFINS (CF, art. 195, I). 2. Revogação pelo art. 56 da Lei 9.430/96 da isenção concedida às sociedades civis de profissão regulamentada pelo art. $6^{\circ}$, II, da Lei Complementar 70/91. Legitimidade. 3. Inexistência de relação hierárquica entre lei ordinária e lei complementar. Questão exclusivamente constitucional, relacionada à distribuição material entre as espécies legais. Precedentes. 4. A LC 70/91 é apenas formalmente complementar, mas materialmente ordinária, com relação aos dispositivos concernentes à contribuição social por ela instituída. ADC 1, Rel. Moreira Alves, RTJ 156/721. 5. Recurso extraordinário conhecido mas negado provimento. (RE 377457, Relator(a): Min. GILMAR MENDES, Tribunal Pleno, julgado em 17/09/2008, REPERCUSSÃO GERAL - MÉRITO DJe-241 DIVULG 18-12-2008 PUBLIC 19-12-2008 EMENT VOL-02346-08 PP-01774)

A posição adotada pela Suprema Corte, sustentando a inexistência de relação hierárquica entre lei complementar e lei ordinária em matéria tributária e prestigiando a ideia de reserva material constitucionalmente posta, não está indene à crítica.

A tese da distribuição material entre as espécies legais, tomada como barreira à utilização dos demais instrumentos introdutores, é condizente com as leis complementares que fundamentam o exercício de competências da União enquanto ente político. Tome-se como exemplo a competência residual da União para instituição de novos impostos, conforme disposto no artigo 154, I, da Constituição da República. O ente não pode dispor validamente sobre aspectos da regra matriz de incidência tributária do novo imposto por meio de lei ordinária, na medida em que se trata de tema reservado à lei complementar. Essa reserva material impede de maneira absoluta a utilização do instrumento introdutor lei ordinária para tal finalidade. Trata-se da propalada reserva material constitucionalmente posta.

Entretanto, o estabelecimento de normas gerais em matéria de legislação tributária por meio de lei complementar, conforme disposto no artigo 146, III, da Constituição da República, presta-se a definir os lindes para o exercício da competência tributária das pessoas políticas. Por óbvio, isso não inibe a expedição de normas tributárias pelos entes tributantes por meio de lei ordinária. Antes, pressupõe essa expedição.

Se a Constituição da República não criou tributos, conforme as prestigiosas lições de Roque Antonio Carrazza (2013, p. 583), tampouco o Código Tributário Nacional o fez. Assim, a instituição de impostos se sujeita à expedição de norma jurídica pelo Poder Legislativo da pessoa política contendo a previsão da exação in abstracto, pressuposto inarredável para sua imposição válida.

A despeito da exigência de lei complementar para tratar das matérias previstas no artigo 146, III, “a”, da Constituição da República, sem a previsão abstrata dos fatos geradores, bases de cálculo e contribuintes na lei instituidora da pessoa política não há de se falar em imposto validamente criado. Cumpre observar que não há reserva material a impedir a disposição da matéria pelo instrumento 
introdutor lei ordinária. Nesse caso, trata-se apenas de manifestação da superioridade hierárquica do Código Tributário Nacional subordinando a produção da lei ordinária criadora do imposto.

Argumentar que as leis instituidoras não estariam dispondo acerca de normas gerais em matéria de legislação tributária, mas tão somente sobre os critérios relacionados ao imposto criado, apenas reforça a premissa de que essas leis ordinárias encontram seu fundamento material de validade nas normas gerais do Código Tributário Nacional.

Outro caso paradigmático refere-se ao julgamento do RE 556.664/RS (BRASIL, 2008b) pelo Supremo Tribunal Federal, cuja ementa é reveladora:

EMENTA: PRESCRIÇÃO E DECADÊNCIA TRIBUTÁRIAS. MATÉRIAS RESERVADAS A LEI COMPLEMENTAR. DISCIPLINA NO CÓDIGO TRIBUTÁRIO NACIONAL. NATUREZA TRIBUTÁRIA DAS CONTRIBUIÇÕES PARA A SEGURIDADE SOCIAL. INCONSTITUCIONALIDADE DOS ARTS. 45 E 46 DA LEI 8.212/91 E DO PARÁGRAFO ÚNICO DO ART. $5^{\circ}$ DO DECRETO-LEI 1.569/77. RECURSO EXTRAORDINÁRIO NÃO PROVIDO. MODULAÇÃO DOS EFEITOS DA DECLARAÇÃO DE INCONSTITUCIONALIDADE. I. PRESCRIÇÃO E DECADÊNCIA TRIBUTÁRIAS. RESERVA DE LEI COMPLEMENTAR. As normas relativas à prescrição e à decadência tributárias têm natureza de normas gerais de direito tributário, cuja disciplina é reservada a lei complementar, tanto sob a Constituição pretérita (art. 18, § $1^{\circ}$, da CF de 1967/69) quanto sob a Constituição atual (art. 146, b, III, da CF de 1988). Interpretação que preserva a força normativa da Constituição, que prevê disciplina homogênea, em âmbito nacional, da prescrição, decadência, obrigação e crédito tributários. Permitir regulação distinta sobre esses temas, pelos diversos entes da federação, implicaria prejuízo à vedação de tratamento desigual entre contribuintes em situação equivalente e à segurança jurídica. II. DISCIPLINA PREVISTA NO CÓDIGO TRIBUTÁRIO NACIONAL. O Código Tributário Nacional (Lei 5.172/1966), promulgado como lei ordinária e recebido como lei complementar pelas Constituições de 1967/69 e 1988, disciplina a prescrição e a decadência tributárias. III. NATUREZA TRIBUTÁRIA DAS CONTRIBUIÇÕES. As contribuições, inclusive as previdenciárias, têm natureza tributária e se submetem ao regime jurídicotributário previsto na Constituição. Interpretação do art. 149 da CF de 1988. Precedentes. IV. RECURSO EXTRAORDINÁRIO NÃO PROVIDO. Inconstitucionalidade dos arts. 45 e 46 da Lei 8.212/91, por violação do art. 146, III, b, da Constituição de 1988, e do parágrafo único do art. $5^{\circ}$ do Decreto-lei 1.569/77, em face do $\S 1^{\circ}$ do art. 18 da Constituição de 1967/69. V. MODULAÇÃO DOS EFEITOS DA DECISÃO. SEGURANÇA JURÍDICA. São legítimos os recolhimentos efetuados nos prazos previstos nos arts. 45 e 46 da Lei 8.212/91 e não impugnados antes da data de conclusão deste julgamento.

(RE 556664, Relator(a): Min. GILMAR MENDES, Tribunal Pleno, julgado em 12/06/2008, REPERCUSSÃO GERAL - MÉRITO DJe-216 DIVULG 13-11-2008 PUBLIC 14-11-2008 EMENT VOL-02341-10 PP-01886)

No referido julgamento, a Suprema Corte prestigiou a tese de que normas relativas à prescrição e à decadência tributárias têm natureza de normas gerais de direito tributário, cuja disciplina é reservada à lei complementar, negando validade aos artigos 45 e 46 da Lei Ordinária n ${ }^{\circ}$ 8.212/1991, que tratavam de decadência e prescrição tributárias envolvendo os créditos da Seguridade Social.

O Superior Tribunal de Justiça (STJ) teve oportunidade de se manifestar sobre a lei complementar que fundamenta a hierarquia formal em nosso ordenamento jurídico, nos termos da 
Constituição da República. O julgamento do REsp 1.050.430/DF (BRASIL, 2010) revela o reconhecimento pela Egrégia Corte da superioridade formal da Lei Complementar n ${ }^{0}$ 95/1998 em relação às demais espécies normativas. Analisou-se no julgamento em destaque a aplicação do artigo $9^{\circ}$ da mencionada lei complementar. Confira-se a ementa:

TRIBUTÁRIO - IMPOSTO SOBRE A RENDA - PESSOA JURÍDICA - OPERAÇÕES DE MÚTUO ENTRE PESSOAS JURÍDICAS COLIGADAS NÃO-FINANCEIRAS - ART. 77,II, DA LEI 8.981/95 - REVOGAÇÃO PELO ART. 50 DA LEI 9.779/99 - NÃOOCORRÊNCIA - LEI COMPLEMENTAR 95/98 - ART. 9० - EXIGÊNCIA DE REVOGAÇÃO EXPRESSA - ART. 94, III, DA LEI 10.833/2003.1. A isenção do imposto sobre a renda pessoa jurídica, incidente sobre as operações de mútuo entre pessoas jurídicas coligadas e não-financeiras vigorou até o advento da Lei 10.833/2003, que por seu art. 94, III, revogou expressamente o art. 77, II, da Lei 8.981/95.2. A Lei Complementar 95/98 é fundamento de validade formal das demais normas jurídicas e como tal exige que a cláusula de revogação das leis expressamente disponham (sic) sobre os dispositivos incompatíveis com a nova regulamentação da matéria. 3. Recurso especial não provido. (STJ - REsp: 1050430 DF 2008/0088094-6, Relator: Ministra ELIANA CALMON, Data de Julgamento: 02/09/2010, T2 - SEGUNDA TURMA, Data de Publicação: DJe 10/02/2011).

Apreciados esses elementos nem sempre convergentes colhidos na doutrina e na jurisprudência, constata-se, em consonância com os preceitos constitucionais, a existência no ordenamento jurídico de leis complementares que, nos termos da reserva material posta na Constituição da República, prestam-se ao exercício de competências da União enquanto ente político. Por outro lado, coexistindo em harmonia com essas espécies de lei complementar destacam-se outras que fundamentam a validade de leis ordinárias, sendo-lhes hierarquicamente superiores, formal ou materialmente.

Por fim, para concluir as investigações propostas neste trabalho, resta discorrer sobre as nuances da hierarquia material e da hierarquia formal entre lei complementar e lei ordinária em matéria tributária, nos casos em que essas hierarquias se manifestam.

\subsection{HIERARQUIA MATERIAL}

Conforme assentado, a norma jurídica hierarquicamente superior regula a produção das normas que lhe são inferiores. Quando essa regulação define o conteúdo dos demais diplomas normativos, está-se diante de uma relação hierárquica material, quando então as normas jurídicas produzidas buscam seu fundamento de validade nas normas que lhe são superiores.

O artigo 146, III, da Constituição da República, ao dispor que cabe à lei complementar estabelecer normas gerais em matéria de legislação tributária, confere ao Código Tributário Nacional, diploma normativo que atende ao referido preceito constitucional, conforme já consignado, a 
condição de fundamento de validade das leis ordinárias em matéria tributária, assumindo uma posição hierarquicamente superior em relação a elas.

Entretanto, uma análise mais minuciosa da questão revela que a mencionada superioridade hierárquica não se evidencia em razão de sua natureza de lei complementar, como pode parecer à primeira vista. Indícios que corroboram essa afirmação podem ser colhidos ao se buscar o fundamento de validade de leis complementares instituidoras de impostos.

Embora seja usual a afirmação de que lei complementar é materialmente superior a lei ordinária, a assertiva de ser a lei complementar superior a outra lei complementar extrapola as raias da lógica, ferindo o senso comum. A esse respeito, tome-se como exemplo o exercício pela União de sua competência residual, nos termos do artigo 154, I, da Constituição da República, que reclama lei complementar para veiculação de nova exação.

Tratando-se de instituição de imposto pela União no exercício de sua competência residual, indaga-se se o legislador responsável por sua elaboração teria liberdade para inovar em matéria tributária veiculada pelo Código Tributário Nacional. Ainda que de modo intuitivo, tende-se a negar tal prerrogativa a esse legislador. Mas qual seria o fundamento jurídico dessa vedação? Certamente não seria em razão do status de lei complementar atribuído ao Código Tributário Nacional em confronto com a lei complementar instituidora do imposto, na medida em que se trata de diplomas normativos de idêntica conformação. A primazia do Código Tributário Nacional decorre de seu conteúdo de normas gerais. Ainda que a Constituição da República tivesse atribuído à lei ordinária o papel de estabelecer normas gerais em matéria de legislação tributária, leis instituidoras de tributo, ordinárias ou complementares, tampouco poderiam inovar em matéria tributária já tratada por essa lei ordinária de normas gerais. Como assevera Charles William McNaughton (2011, p. 325), norma de ordem parcial não pode se voltar contra norma nacional.

O mesmo raciocínio deve ser reservado ao cotejo entre o Código Tributário Nacional e as leis complementares nacionais editadas por reclamo constitucional para uniformizar o tratamento dispensado a impostos específicos como o ICMS (Lei Complementar $n^{\circ}$ 87/1996) e o ISSQN (Lei Complementar $n^{\circ}$ 116/2003). Inobstante seu conteúdo de normas gerais, não se pode atribuir a essas leis complementares nacionais primazia sobre o Código Tributário Nacional. Nas oportunas ponderações de Renata Elaine Silva (2013, p. 47), pensar de modo diverso atentaria contra o princípio da isonomia entre as pessoas políticas de direito público, dando ensejo à criação de normas mais favoráveis para determinados entes tributantes em detrimento dos demais. Afinal, embora veiculem normas gerais com relação às exações apontadas, não preservam tal condição ante o sistema tributário nacional. 
Como arremate, constata-se que Eduardo Marcial Ferreira Jardim (1996, p. 103) aproximouse do deslinde da questão. Nada obstante a sua rejeição com relação à existência de hierarquia por conteúdo entre lei complementar e lei ordinária, o autor assim pontuou:

Ao demais, inexiste também hierarquia por conteúdo em prol da legislação complementar em relação à legislação ordinária. O que existe, por vezes, é a preeminência de um dado diploma normativo em relação a outros, não em face da natureza complementar, mas em virtude de seu conteúdo de legislação nacional que desfruta de preeminência em relação aos planos normativos federal, estadual, distrital e municipal.

Assim, conclui-se que a superioridade material da lei complementar em relação à lei ordinária em matéria tributária não decorre de sua natureza e sim de seu conteúdo de normas gerais, que, em princípio, poderiam ter sido veiculadas por meio de lei ordinária, se assim o desejasse o legislador constituinte, sem prejuízo da supremacia dessa lei ordinária em relação aos demais diplomas normativos. Constata-se, portanto, ser apenas reflexa a superioridade hierárquica de lei complementar em relação a lei ordinária em matéria tributária.

\subsection{HIERARQUIA FORMAL}

Na medida em que a produção das normas jurídicas pode envolver questões de forma e conteúdo das unidades produzidas, abre-se espaço para que o tema da hierarquia entre normas também possa ser examinado em seu aspecto formal. Assim, pode-se definir hierarquia formal como a relação existente entre duas ou mais normas por meio da qual uma delas fornece os fundamentos de validade das demais com relação à sua forma de elaboração.

A Constituição da República define em seu artigo 59, parágrafo único, que lei complementar disporá sobre a elaboração, redação, alteração e consolidação das leis. Em atendimento ao comando constitucional, foi elaborada a Lei Complementar $n^{\circ}$ 95/1998, que, logo em seu artigo $1^{\text {o }}$, parágrafo único, prescreve que as suas disposições aplicam-se aos atos normativos do artigo 59 da Constituição da República e ainda aos decretos e aos demais atos regulamentares do Poder Executivo, no que couber. Do exposto, conclui-se que a Lei Complementar no 95/1998 é formalmente superior aos demais diplomas legislativos, em especial àqueles elencados no artigo 59 da Lei Maior.

Entretanto, assim como demonstrado em relação à hierarquia material, uma análise mais minuciosa da questão revela que a mencionada hierarquia formal não se evidencia em razão da natureza da lei complementar, como pode parecer à primeira vista.

Se, conforme explanado, extrapola as raias da lógica a assertiva de ser a lei complementar superior a outra lei complementar, ainda mais paradoxal seria afirmar que a lei complementar é 
superior às emendas constitucionais, cujo processo de elaboração também deve obediência às disposições da Lei Complementar $n^{\circ}$ 95/1998, nos termos de seu artigo $1^{\circ}$.

Percebe-se, afinal, que a superioridade formal da lei complementar em relação à lei ordinária em matéria tributária não decorre de sua natureza e sim de seu conteúdo, que, assim como na hierarquia material, poderia ter sido veiculado por meio de lei ordinária, se assim o desejasse o legislador constituinte, sem prejuízo da supremacia dessa lei ordinária em relação aos demais diplomas normativos. Aqui, também, constata-se ser apenas reflexa a superioridade hierárquica da lei complementar em relação à lei ordinária em matéria tributária.

\section{CONCLUSÃO}

Diante do exposto, pode-se inferir que a escolha da lei complementar pelo legislador constituinte para o estabelecimento de normas gerais em matéria de legislação tributária e para disciplinar o processo de elaboração, redação, alteração e consolidação das leis teve como fundamento a maior rigidez no rito de aprovação desse diploma normativo. Em princípio, não haveria óbices a que o legislador tivesse escolhido a lei ordinária com pretensões de tal espécie.

Breve exame do sistema jurídico revela que os preceitos dos artigos 146, III, e 59, parágrafo único, da Constituição da República foram satisfeitos por meio do Código Tributário Nacional e pela expedição da Lei Complementar n ${ }^{\circ}$ 95/1998. Se por um lado o papel atribuído às mencionadas leis sugere a existência de superioridade hierárquica da lei complementar em relação à lei ordinária em matéria tributária, por outro lado, a existência de diversos comandos constitucionais que reclamam a edição de lei complementar em temas tributários parece refutar tal assertiva.

Com efeito, vislumbram-se na tessitura do sistema jurídico duas ordens de lei complementar em matéria tributária: aquela alçada a fundamento de validade de outros diplomas normativos e aqueloutra manejada para o exercício de competências da União enquanto ente político. Conclui-se, desse modo, que não se pode defender uma visão unitária sobre a superioridade hierárquica de lei complementar sobre lei ordinária em matéria tributária.

Ao se desincumbir de seu encargo constitucional, o legislador vai inserir no sistema jurídico as duas referidas ordens de lei complementar e desvendar a dinâmica envolvendo essas ordens. Enquanto a função da lei complementar reservada ao exercício de competências da União na qualidade de ente político se exaure com sua edição, o Código Tributário Nacional e a Lei Complementar ${ }^{\circ}$ 95/1998 vão servir de fundamento para a expedição das leis instituidoras de tributos pelas pessoas políticas. A previsão in abstracto dos caracteres da regra matriz de incidência tributária 
nas leis instituidoras dos tributos, pressuposto inarredável para imposição válida da exação, conforma-se ao disposto nas leis complementares que lhe servem de fundamento.

Convém notar que o exercício de competências da União na qualidade de ente político está sujeito à reserva material constitucionalmente posta, não se podendo cogitar da utilização de outro instrumento introdutor de normas jurídicas se lei complementar for exigida. Por seu turno, o estabelecimento de normas gerais em matéria de legislação tributária por meio de lei complementar pressupõe a expedição das leis instituidoras de tributos pelas pessoas políticas, que naquela buscam fundamento para criação dos caracteres da regra matriz de incidência tributária.

Na medida em que essas leis instituidoras de tributos podem assumir a feição de lei complementar ou lei ordinária, nos termos constitucionais, abre-se espaço para indagações acerca da natureza da superioridade hierárquica do Código Tributário Nacional. Em reforço a essas indagações, vale ressaltar que, em seu processo de elaboração, as emendas constitucionais se curvam aos imperativos da Lei Complementar nº 95/1998.

Deveras, o fundamento da superioridade hierárquica da lei complementar em matéria tributária radica-se em seu conteúdo, não guardando relação alguma com sua forma, nada obstante tê-la escolhido o legislador constitucional em razão da maior rigidez no rito de aprovação desse diploma normativo.

Em conclusão, a despeito da demonstração da superioridade hierárquica do Código Tributário Nacional e da Lei Complementar n 95/1998 em relação às leis ordinárias em matéria tributária, a partir das investigações empreendidas foi possível desvelar a natureza apenas reflexa dessa superioridade. Em respeito ao rigor científico cumpre reconhecer que o fundamento da superioridade hierárquica material e formal observada não se radica no caráter formal das leis complementares examinadas, mas tão somente em seu conteúdo.

\section{REFERÊNCIAS}

ATALIBA, Geraldo. Normas gerais de direito financeiro e tributário e autonomia dos estados e municípios. Revista de Direito Público, [s. l.], n. 10, p. 45-80, out./dez. 1969.

BASTOS, Celso Ribeiro. Lei complementar: teoria e comentários. São Paulo: Instituto Brasileiro de Direito Constitucional, 1999.

BORGES, José Souto Maior. Lei complementar tributária. São Paulo: Editora Revista dos Tribunais, 1975. 
BRASIL. Constituição da República Federativa do Brasil de 1988. Diário Oficial da União, Brasília, DF, 5 de outubro de 1988. Disponível em: https://bit.ly/2DSgHYs. Acesso em: 19 jun. 2019.

BRASIL. Lei Complementar No 95, de 26 de fevereiro de 1998. Dispõe sobre a elaboração, a redação, a alteração e a consolidação das leis, conforme determina o parágrafo único do art. 59 da Constituição Federal, e estabelece normas para a consolidação dos atos normativos que menciona. Diário Oficial da União, Brasília, DF, 27 fev. 1998. Disponível em: https://bit.ly/33Vaaa0. Acesso em: 19 jun. 2019.

BRASIL. Superior Tribunal de Justiça. Recurso Especial n ${ }^{\circ}$ 1.050.430/DF. Recorrente: Fazenda Nacional. Recorrido: Celulose Nipo Brasileira S.A. CENIBRA. Segunda Turma. Relatora: Ministra Eliana Calmon. Data do Julgamento: 2 set. 2010. DJe, 10/02/2011, RDDT vol. 188, p. 157. Disponível em: http://bit.ly/2s8MamI. Acesso em: 19 maio 2019.

BRASIL. Supremo Tribunal Federal. RE 377.457/PR. Recorrente: Antônio Glênio F. Albuquerque \& Advogados Associados S/C. Recorrido: União. Tribunal Pleno. Repercussão Geral. Relator: Ministro Gilmar Mendes. DJE nº 175, divulgado em 16/09/2008a. Disponível em: http://bit.ly/344Az5l. Acesso em: 19 maio 2019.

BRASIL. Supremo Tribunal Federal. RE 556.664/RS. Recorrente: União. Recorrido: Novoquim Indústria Químicas Ltda. Tribunal Pleno. Repercussão Geral. Relator: Ministro Gilmar Mendes. Brasília, julgado em 12 jun. 2008, DJ Nr. 151 do dia 14/08/2008b. Disponível em: http://bit.ly/2YyD1A3. Acesso em: 19 maio 2019.

CARRAZZA, Roque Antonio. Curso de direito constitucional tributário. 29. ed. rev. ampl. e atual. até a emenda constitucional n. 72/2013. São Paulo: Malheiros, 2013.

COSTA, Regina Helena. Curso de direito tributário: Constituição e Código Tributário Nacional. 4. ed. São Paulo: Saraiva, 2014.

GUIBOURG, Ricardo A.; GHIGLIANI, Alejandro M.; GUARINONI, Ricardo V. Introducción ao conocimiento científico. 8. ed. Buenos Aires, Argentina: Eudeba, 1991.

HOSPERS, John. Introducción al análisis filosófico. Madrid: Alianza Editorial, 1976.

JARDIM, Eduardo Marcial Ferreira. Dicionário jurídico tributário. 2. ed. rev. e atual. São Paulo: Saraiva, 1996.

MACHADO, Hugo de Brito. Lei complementar tributária. São Paulo: Malheiros, 2010.

MCNAUGHTON, Charles William. Hierarquia e sistema tributário. São Paulo: Quartier Latin, 2011.

MOURA, Frederico Araújo Seabra de. Lei complementar tributária. São Paulo: Quartier Latin, 2009.

SILVA, Renata Elaine. Curso de decadência e prescrição no direito tributário: regras do direito e segurança jurídica. São Paulo: Noeses, 2013. 
SOUSA, Rubens Gomes de; ATALIBA, Geraldo; CARVALHO, Paulo de Barros. Comentários ao Código Tributário Nacional: parte geral. 2. ed. São Paulo: Quartier Latin, 2007.

TEMER, Michel. Elementos de direito constitucional. 24. ed. rev. e atual. 2. tiragem. São Paulo: Malheiros, 2014.

Paulo de Barros Carvalho Professor Titular e Emérito na PUC-SP e na USP. Membro Titular da Academia Brasileira de Filosofia. Advogado. E-mail: paulo@barroscarvalho.com.br

Sérgio Serafim Aquino Agente Fiscal de Rendas na Secretaria da Fazenda e Planejamento do Estado de São Paulo. Graduado pela Faculdade de Direito da Pontifícia Universidade Católica de Campinas. Especialista em Direito Tributário pelo Instituto Brasileiro de Estudos Tributários. E-mail: sergiosaquino@yahoo.com.br 